\title{
Swelling Behavior of Halthane 73-18 Polyurethane Adhesive in Dimethyl Sulfoxide (DMSO)
}

\author{
James D. LeMay
}

June 1996

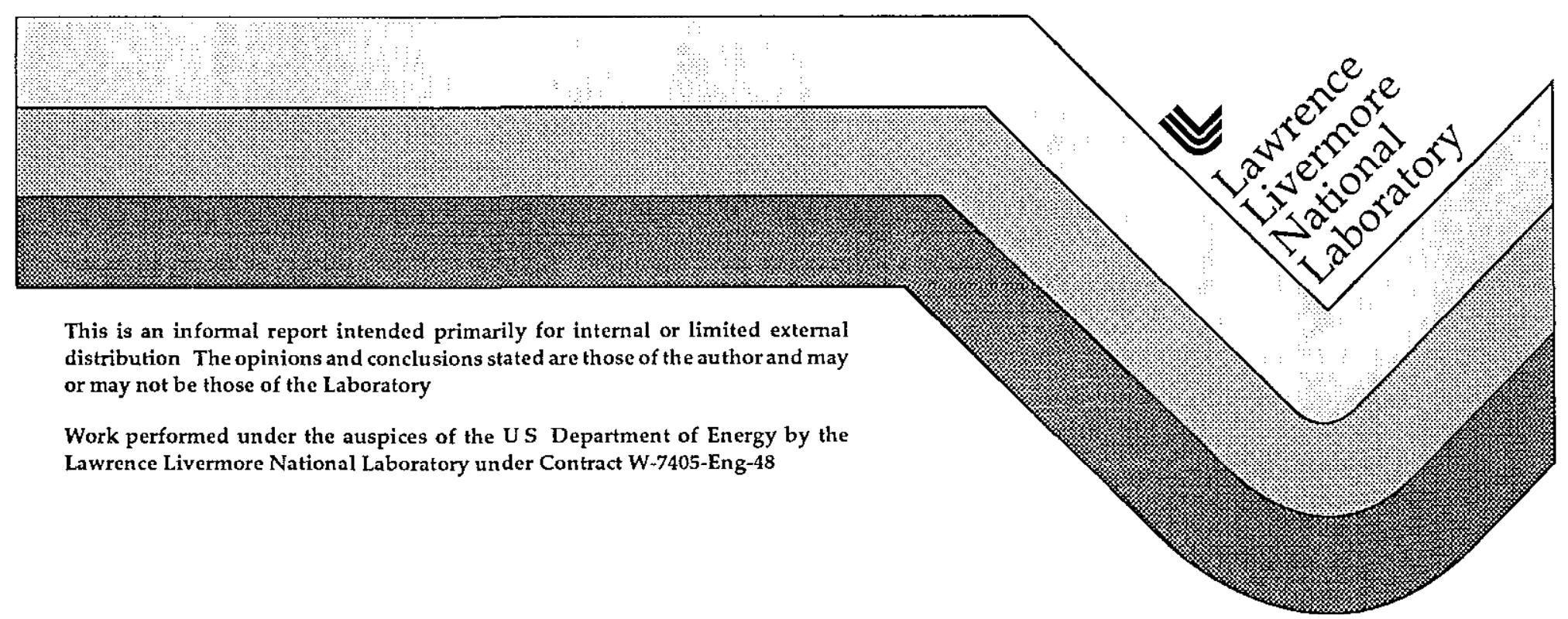




\title{
SWELLING BEHAVIOR OF HALTHANE 73-18 POLYURETHANE ADHESIVE IN DIMETHYL SULFOXIDE (DMSO)
}

\author{
James D LeMay \\ Lawrence Livermore National Laboratory \\ Livermore, CA 94550
}

June 1996 


\title{
SWELLING BEHAVIOR OF HALTHANE 73-18 POLYURETHANE ADHESIVE IN DIMETHYL SULFOXIDE (DMSO) ${ }^{*}$
}

\author{
James D. LeMay \\ Lawrence Livermore National Laboratory
}

\section{Introduction}

To insure safe performance during the launch and flight of the W79 Artillery Fired Atomic Projectile (AFAP), the assembly gaps in the high explosive assembly were filled with a continuous film of polyur ethane elastomer adhesive called Halthane 73-18 To disassemble bonded weapons like the W79, Lawrence Livermore and Mason \& Hanger, Pantex Plant have developed a chemical dissolution process that safely removes the high explosive, thereby facilitating the recovery of the pit The solvent of choice for the W79 AFAP was dimethyl sulfoxide (DMSO)

In the W79 dissolution process, a continuous spray of DMSO is emitted through nozzles mounted in manifold assembly that encircles the HE assembly The operating pressure and temperature of the DMSO are less than 100 psig and less than $160^{\circ} \mathrm{F}$ Although warm DMSO readily dissolves the LX-10 explosive, it cannot dissolve the Halthane 73-18 adhesive due to its chemically crosslinked structure DMSO does, however, swell the Halthane adhesive The resulting swollen films are soft and unable to support their own weight, yet they are not necessarily so fragile that they will tear or shred readily under the force of the DMSO spray Indeed, the swollen Halthane films encountered in several W79 Type 6B units tested in the Pantex Workstation proved to be quite tenacious They remained intact under the action of DMSO spray and became an encapsulating barrier that shielded the remaining undissolved $\mathrm{HE}$ This effectively stopped the dissolution process, forcing manual removal in order to complete the dissolution process By comparison, the swollen Halthane film was readily shredded and eliminated under the action of the DMSO spray nozzles in tests at LLNL in workstation of a different design This apparent difference in response is the subject of this report

\section{Background}

At the time that the work described in this report was being performed, two dissolution workstation designs were being evaluated for possible use in the W79 AFAP dismantlement program, one at Pantex her ein called the Pantex Workstation, and the other at Site 300 at Lawrence Livermore National Laboratory herein called the LLNL Workstation Since this time, the LLNL-designed workstation was selected for the W79 Dismantlement Program and it is currently being installed at Pantex Although the final version of the LLNL Workstation contains some significant design changes from the development version used in this study, the general dissolution process and the DMSO spray conditions remain the same

At the time of the tests described in this report (Spring/Summer 1994) thet e were several potentially significant differences between the Pantex and LLNL Workstations These included 1) the DMSO pump

\footnotetext{
* Work performed under the auspices of the U S Department of Energy by Lawrence Livermore National Laboratory under Contract No W-7405-Eng-48

${ }^{1} \mathrm{LX}-10$ is $95 \mathrm{wt} \% \mathrm{HMX}, 5 \mathrm{wt} \%$ Viton-A
} 
pressure, 2) the orientation of the spiay nozzles, 3) the spray nozzle patterns, and 4) the origin of the test W79 assemblies More details of these differences are now discussed

The LLNL Workstation employed a higher pump pressure than Pantex Workstation, about 65 psig versus $\sim 35$ psig Pantex apparently opted to employ a lower pressure out of concern for the longevity of their pump Combined with a higher flow rate and an optimized nozzle pattern employed in the spray manifold, it appeared that the DMSO in the LLNL system was capable of applying more force and thereby doing more work on the swollen Halthane film (i e , tearing and shredding)

In the Pantex Workstation, the orientation and low delivery pressure of the spray nozzles permitted the Halthane film to drape over the assembly and shield the undissolved HE from the DMSO spray This effectively stopped the dissolution process In contrast, the LLNL Workstation used a nozzle orientation and delivery pressure that facilitated the dissolution process by shredding the Halthane and allowing DMSO to rapidly drain away from the assembly, thus continuously exposing the undissolved HE to the DMSO spray

One last possible difference -- the one addressed in this study -- was that there was some difference in the Halthane 73-18 adhesives in the W79 units tested in the LLNL Workstation versus those tested in the Pantex Workstation In development testing, LLNL used freshly built non-nuclear assemblies constructed at Site 300, whereas the Type 6B W79 units used by Pantex were "naturally aged" flight test units that were built at the same time as the W79 warheads Because polymers can undergo chemical changes during aging, such as degradation and/or crosslinking, it was deemed a possibility that the Halthane 73-18 in the LLNL assemblies might not be representative of the materials in older Type 6B units For this reason the effects of thermally accelerated and natural aging on the swelling behavior of Halthane 73-18 were examined in this study

\section{Experimental}

\section{Specimens}

Five types of Halthane 73-18 specimens were evaluated in this investigation

- DMSO Swollen Films were recovered from W79 assemblies tested at Pantex and LLNL

- Retention Samples were recovered from kit mixes used to assemble LLNL test units at Site 300

- Lab-Prepared Halthane samples were at LLNL in the form of molded sheets/films $0005-020$ in thick, and bulk slabs 016 in thick

- A slab sample of seventeen-year-old "Natur ally Aged" Halthane was obtained from Y12 2 These were prepared at room temperature (R T ) in 1977 and thereafter stored in the lab under ambient conditions

- "Used" Films ( 0005 in thick) were recovered from Halthane bonded lap shear specimens that were prepared and tested at LLNL

\section{Swelling Properties}

Simple swelling and drying measurements were carried out on dry and swollen Halthane 73-18 specimens using pure DMSO These specimens typically were between $02-1$ gram in mass Equations 1-3 describe the properties measured The "sol fraction" described by Equations 3 and 4 is that portion of the Halthane that is extracted from the sample by the DMSO The sol fraction is a function of the weight gain on swelling and weight loss on drying as shown in Equation 4 Note that the sol fraction and

\footnotetext{
2 Provided by George Dorsey at the Y 12 Plant in Oak Ridge
} 
weight gain on swelling and weight loss on drying as shown in Equation 4 Note that the sol fraction and weight gain cannot be measured for swollen films recovered from the Pantex and LLNL Workstations because the initial dry weight, $\mathrm{W}_{0}$, is unknown

Measured Swelling Properties

\begin{tabular}{|c|c|c|c|c|}
\hline 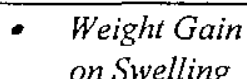 & Gain (wt $\%)$ & $=100 \times\left(W_{w}-W_{0}\right) / W_{o}$ & Positive value & $\overline{E q} 1$ \\
\hline $\begin{array}{l}\text { - Weight Loss } \\
\text { on Drying }\end{array}$ & Loss $(w t \%)$ & $=100 \times\left(W_{d}-W_{w}\right) / W_{w}$ & Negative value & $\mathrm{Eq} 2$ \\
\hline - Sol Fraction & Sol (wt \%) & $\begin{array}{l}=100 \times\left(W_{d}-W_{o}\right) / W_{o} \\
=100 \times((1+G a i n / 100)(1-\text { Loss } / 100)-1)\end{array}$ & Negative value & $\begin{array}{ll}\text { Eq } 3 \\
\text { Eq } 4\end{array}$ \\
\hline
\end{tabular}

To obtain the equilibrium swollen weight, $\mathrm{W}_{\mathrm{w}}$, the following procedure was used 1) Measure initial (dry) weight, $W_{0} \quad 2$ ) Immerse in neat DMSO in a tightly sealed glass vial for $24-48$ hours at $50^{\circ} \mathrm{C}$ (elevated temperature used to accelerate equilibrium swelling) 3) Remove vial from oven and allow to cool to room temperature 4) Remove specimen from DMSO with forceps and pat dry on lintless paper towel to remove excess liquid DMSO 5) Weigh to get $\mathrm{W}_{\mathrm{w}}$

To obtain the weight loss on drying, $W_{d}$, the following procedure was used 1) Place swollen specimen on a piece of pre-weighed aluminum foil, 2) Dry specimen in $50^{\circ} \mathrm{C}$ forced-air oven for $16-24$ hours 3) Transfer specimen to $50^{\circ} \mathrm{C}$ vacuum oven for final drying 4) Weigh specimen periodically to constant weight 5) Obtain $W_{d}$ by subtracting weight of foil Prior to using this procedure on the samples recovered from dissolution test units at Pantex and LLNL, the specimens were soaked overnight several times in clean DMSO to exchange any residual LX-10/DMSO solution with clean DMSO

\section{Aged Samples}

It was previously noted that naturally aged lab specimens of 1977 vintage were obtained for testing ${ }^{2}$ In an attempt to simulate the additional postcuring and physical chemical changes that might occur over time in the stockpile, some of the Lab-Prepared Halthane 73-18 samples were subjected to accelerated thermal aging These specimens were aged in a forced air oven at 50 and $70^{\circ} \mathrm{C}$ for durations up to 21 days

\section{Results \& Discussion}

Appendix A gives information on the composition and preparation of Halthane 73-18 As a familiarity with the microstructure of Halthane 73-18 will aid in subsequent discussions, a conceptual diagram of the network structure is shown in Figure $1^{3}$ Halthane 73-18 is a "segmented" polyurethane, meaning that it is characterized by a morphology containing microphases of "hard" glassy segments and "soft" flexible chain segments Elastomers with this type of morphology exhibit properties typical of crosslinked elastomers because the hard segments function as tie-points (or crosslinks) for the flexible soft segments If crosslinking chemistry is not utilized, this segmented morphology also provides unique processibility since the hard segments can be melted to yield a reformable thermoplastic polymer Halthane 73-18, however, is crosslinked and thus it retains good network properties even at temperatures above the melting point of the hard segments

${ }^{3}$ L R Althouse and N W Hetherington, "Study of the Aging processes in Polyurethane Adhesives Using Thermal Treatment and Differential Calorimetric, Dielectric, and Mechanical Techniques I. Identifying the Aging Process II Quantifying the Aging Effect," LLNL, UCRL-52849, November, 1979 


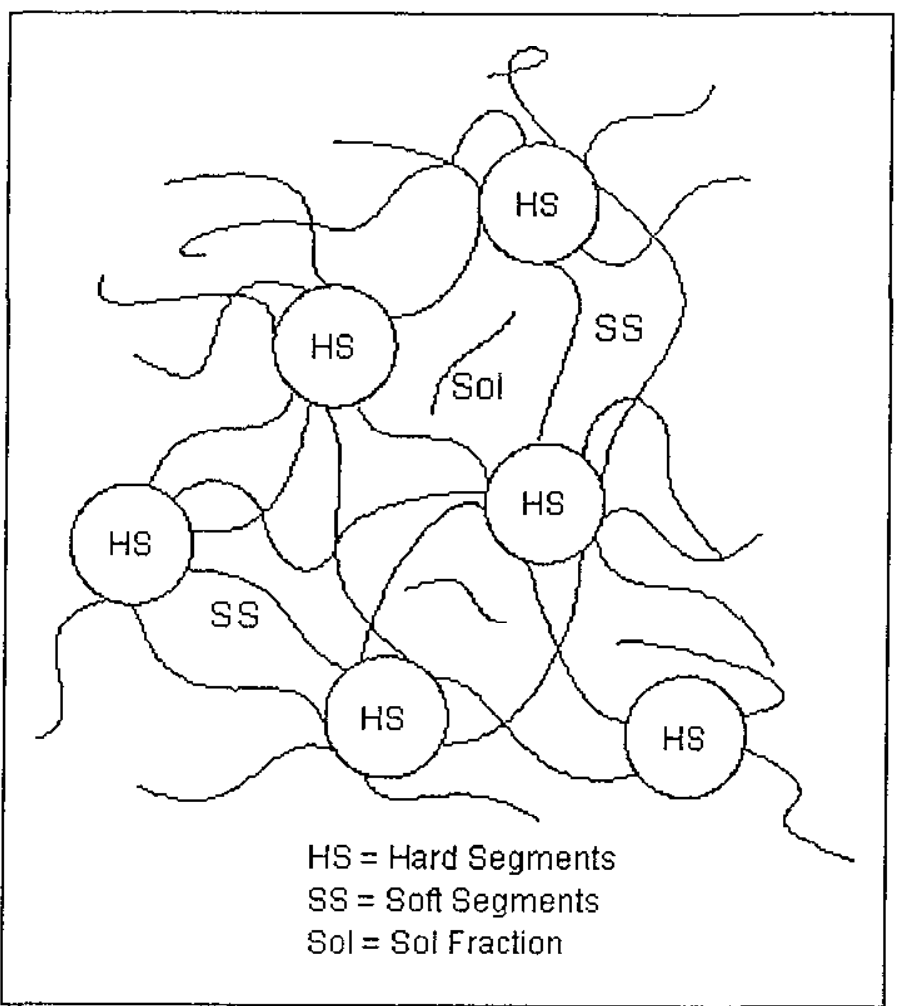

Figure 1 Segmented polyur ethane structure comprised of hard and soft segment domains

Unattached network material, or "sol," is shown in Figure 1 This material can have several origins, for example, off-stoichiometry cure chemistry (e g, from inaccurate weighing, or incomplete mixing), reactions with atmospheric contaminants (especially water), or reactions with species on the surface of a substrate (if, say, the material is used as an adhesive) If "sol" is present in Halthane 73-18 then it may be extracted during DMSO swelling/drying experiments The presence of sol may be important because it implies that the network does not contain the maximum concentration of crosslinks This coupled with the extraction of the sol by a solvent may render the network weakened and possibly more susceptible to mechanical damage, say by the action of DMSO spray

If Halthane is prepared under strictly controlled conditions with identical starting materials and similar cure conditions, then different batches should exhibit nearly identical morphologies and network characteristics We would expect that such batches would also exhibit consistent swelling behavior Our findings, however, revealed a situation that was far removed from this ideal Figure 2 shows swelling results (as percent weight gain) for various Retention samples of Halthane 73 adhesive These samples were cured at ambient (room temperature), and several were subjected to elevated temperature postcures We included several Halthane 73-19 samples in this study because this adhesive is identical in composition to 73-18, except for the addition of a catalyst to accelerate the cure 4

DMSO-induced swelling of Halthane 73 adhesives appears to span a wide range of weight gains (130$360 \mathrm{wt} \%$ ) This cannot be attributed to rate effects, as the data clearly shows that equilibrium swelling is essentially attained in these small specimens after just 24 hours of immersion in DMSO at $50^{\circ} \mathrm{C}$ The

\footnotetext{
${ }^{4} \mathrm{H} \mathrm{G}$ Hammon, L P Althouse, and D M Hoffman, "Development of Halthane Adhesives for Phase 3 Weapons Summary Report," LLNL, UCRL-52943, December 1980
} 
data in Figure 2 also shows that that the swelling behavior does not correlate with sample age Indeed, in two cases, multiple batches made on the same day exhibited significantly different swelling behaviors (20-Oct-93 and 5-Nov-93 specimens) Finally, the data also suggests that postcuring has little effect on the swelling behavior (the two 1-Oct-93 Halthane 73-19 samples) We will revisit the apparent effects of postcuring on swelling later in this section

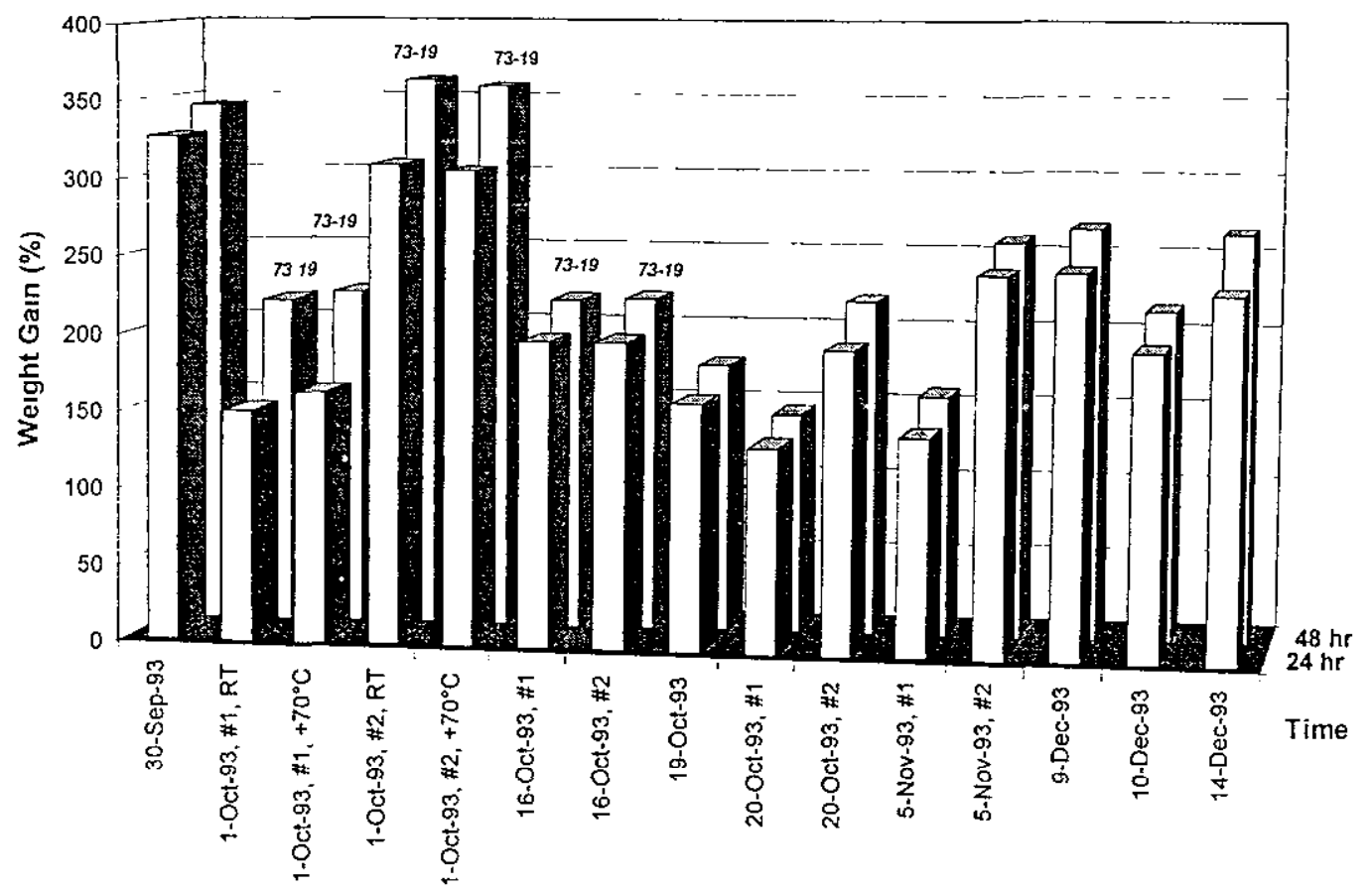

Figure 2 Swelling results for various Halthane 73-18 Retention specimens as function of immersion time (The Halthane 73-19 labeled data is discussed in the text)

Figure 3 and Table 1 show swelling data for four Halthane 73-18 films recovered from W79 units processed in the Pantex and LLNL Workstations Also shown are swelling data for a half dozen labprepared Halthane specimens As previously noted, it is unfortunate that weight gain and sol fraction values could not be obtained from the recovered workstation films because their initial dry weight is unknown We will now discuss four observations from the data in Figure 3 and Table I

First, the Type 6B films recovered from the Pantex and LLNL Workstations appear to be the least swollen of all the films evaluated (i e, lowest weight loss on drying) The two films recovered from the LLNL-built W79 units (DTU79-3, -5) do not appear to be significantly different from the various labprepared samples The results for the Type $6 \mathrm{~B}$ films could be interpreted as a confirmation of Pantex's experience with Type 6B units, $\mathrm{i}$ e, that the Halthane is more difficult to eliminate We are hesitant, however, to arrive at this conclusion based on such a limited set of data, especially since the W79 Type $6 \mathrm{~B}$ unit evaluated in the LLNL Workstation did not prove to be any more difficult to process than the LLNL-built units The practical issue, however, is how easily the films are destroyed by the action of the DMSO spray Although we never recovered very large pieces of swollen films, our simple handling tests (with forceps) did not distinguish any revealing differences in the appearance, strength or toughness of the films Our primary observation from these handling experiments was that all the films were very easy to tear or shred once nicked 


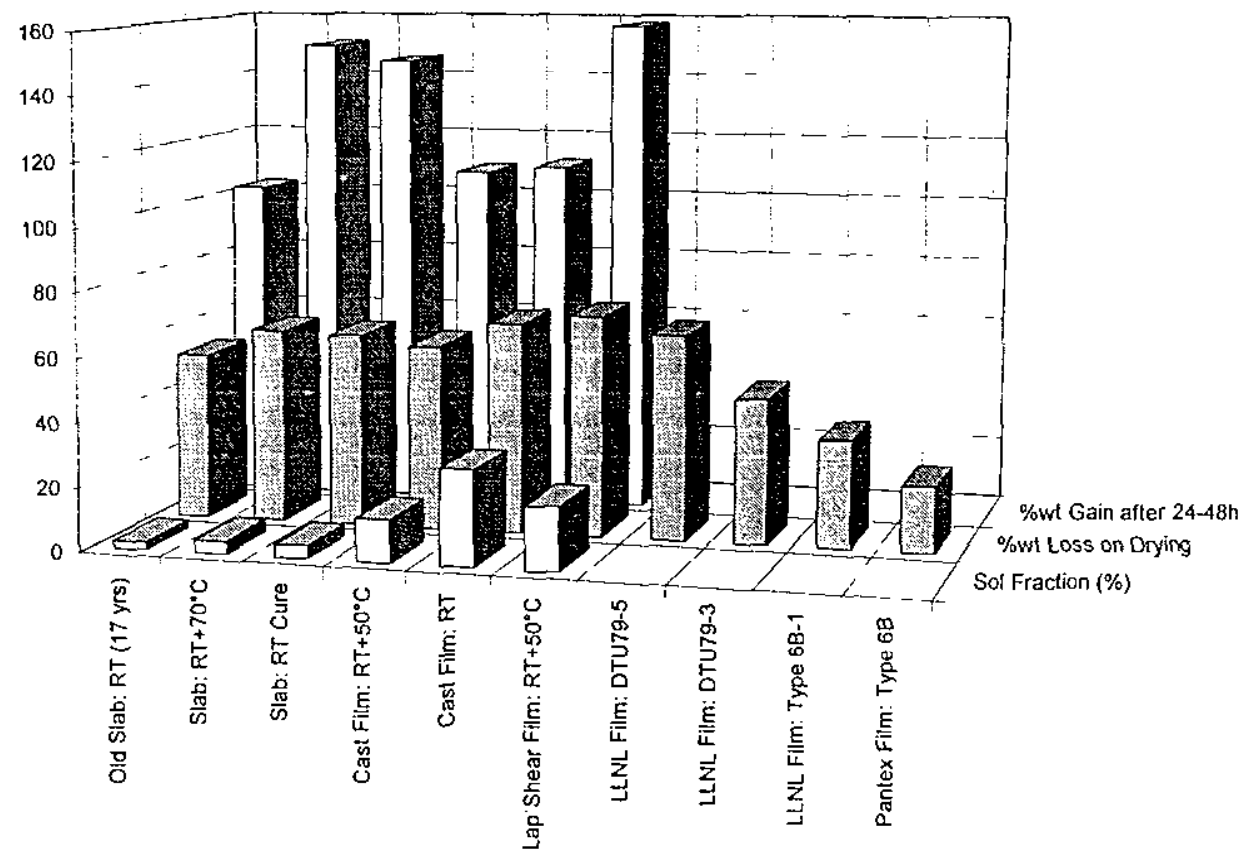

Figure 3 Swelling results on various Halthane 73-18 specimens The four specimens on the right were recovered from actual W79 dissolution test runs

Table I Swelling results on various Halthane 73-18 specimens

\begin{tabular}{|l|c|c|c|c|}
\hline \hline Sample Description & $\begin{array}{c}\text { Gain } \\
(w t \%)\end{array}$ & $\begin{array}{c}\text { Loss } \\
(w t \%)\end{array}$ & $\begin{array}{c}\text { Sol } \\
(w t \%)\end{array}$ & Source \\
\hline \hline Old Slab 17years @ R T & 102 & 527 & 25 & Y-12 \\
\hline Slab R T Cure & 146 & 609 & 38 & B222 \\
Slab R T +21 days @, 70 C & 151 & 615 & 38 & B222 \\
\hline Cast Film R T Cure & 111 & 664 & 296 & B222 \\
Cast Film R T +7 days @, 50 C & 109 & 584 & 131 & B222 \\
\hline Lap-shear Film R T +4 days @, 50 C & 158 & 693 & 196 & S300 \\
\hline Recovered Film, LLNL DTU79-5 & & 644 & & S300 \\
Recovered Film, LLNL DTU79-3 & & 457 & & S300 \\
Recovered Film, LLNL Type 6B-1 & & 340 & & S300 \\
\hline Recovered Film, PX Type 6B & \multicolumn{2}{|l}{208} & & Pantex \\
\hline
\end{tabular}

Our second observation from the data in Figure 3 is that aging, whether naturally or thermally induced, appears to have no significant effect on the swelling behavior of Halthane 73-18 Comparing the DMSO swelling of the 17-year old Y12 slab specimen to the LLNL-prepared slab suggests that reduced swelling might accompany aging, however, laboratory aging of a lab-prepared slab at modest temperatures failed to reproduce this result On the other hand, results for the Cast Film in Table I, show no significant change in swelling, but there is evidence that that the amount of sol is reduced after aging For this reason we carried out additional experiments to determine the effects of elevated temperature postcuring/aging on bonded films of Halthane 73-18 
Figures 4 and 5 show the effects of 50 and $70^{\circ} \mathrm{C}$ elevated temperature exposure, or postcure, on both the swelling behavior and bond strength of thin adhesive films of Halthane 73-18 prepared in a lap-shear configuration on aluminum adher ends The swelling tests were performed on the adhesive films recovered from the lap-shear specimens after testing The range of the weight gains measured for these samples (120-230 wt\%) were consistent with the values shown in Figures 1 and 3 The data in Figures 4 and 5 show conclusively that postcuring has no effect on the lap-shear bond strength and swelling behavior of Halthane 73-18 Increased bond strength and reduced swelling are two results we would expect to see if postcuring was causing additional curing or crosslinking Conversely, if postcuring was causing degradation of the Halthane network, we would expect to see reduced bond strength and increased swelling Neither of these trends are clearly exhibited by the experimental data

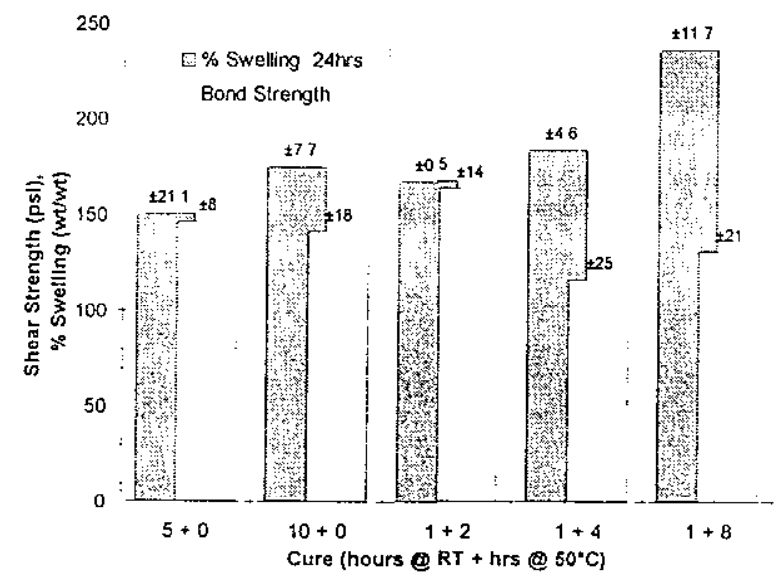

Figure 4 Halthane 73-18 lap shear strength and weight gain in DMSO as function of cure at room temperature and postcure at $50^{\circ} \mathrm{C}$ (Note Weight loss on drying and sol fraction data for the " $1+4$ " film is shown in Figure 3 and Table I)

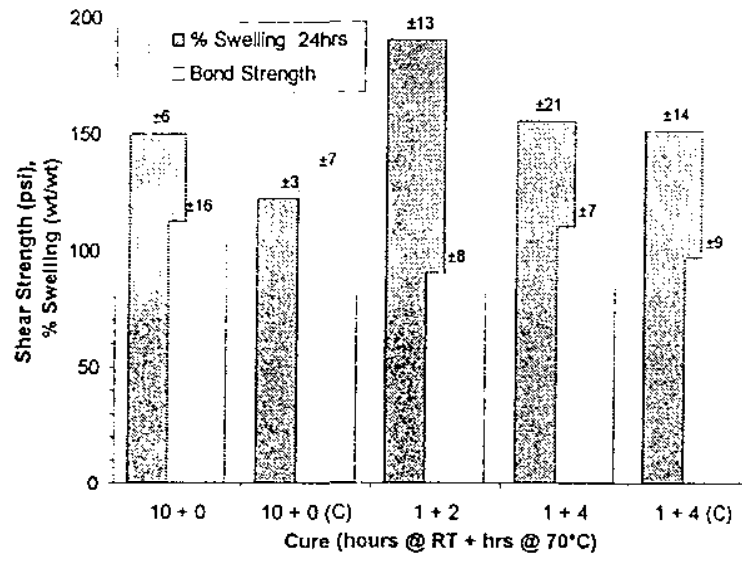

Figure 5 Halthane 73-18 lap shear strength and weight gain in DMSO as function of cure at Room temperature and postcure at $70^{\circ} \mathrm{C}(" \mathrm{C} "$ denotes degassed batches of adhesives )

Returning again to Figure 3, our third observation is that larger sol fractions are observed in the films than in the bulk samples in Figure 3 One reasonable explanation for this is that the high surface-tovolume ratio of films makes them more susceptible to contamination by atmospheric and adsorbed surface moisture For example, adsorbed water could react with the isocyanate functional groups and reduce the curing and crosslinking functionality This, in turn, could result in an increased sol fraction because pre-reacted molecules cannot be fully incorporated into the network structure

Our fourth and final observation from Figure 3 is that there is a weak correlation between weight gain on swelling and weight loss on the drying of swollen Halthane 73-18 (Figure 6) The curves plotted in Figure 6 show the relationship between weight gain and weight loss as a function of sol fraction (Equation 4) 


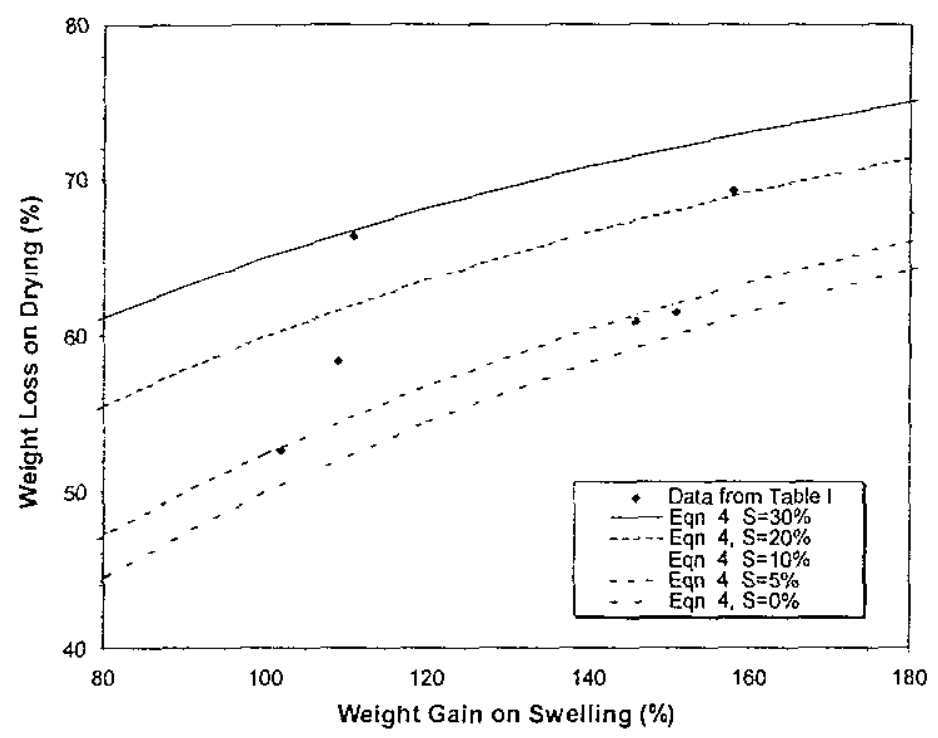

Figure 6 Correlation between weight gain on swelling and weight loss on drying for samples listed in Table I The curves represent Equation 4 with sol fractions (S) ranging from $0-30 \mathrm{wt} \%$

\section{Conclusions}

No definitive chemical or aging phenomena were identified to explain the differences observed in the behavior of DMSO-swollen films of Halthane 73-18 in the LLNL and Pantex HE Dissolution Workstations The most likely explanation would appear to be that the less vigorous DMSO spray conditions in the Pantex Workstation were insufficient to shred and eliminate the swollen Halthane film

If a material property of Halthane was a factor for the observed difference in behavior, we can only speculate that might be due a difference in sol fractions in the adhesive films The argument would be that that different sol fractions might influence the ease with which swollen films of Halthane could be torn apart under the action of DMSO spray The presence of a large fraction of sol in a Halthane 73-18 network could indicate poor curing and incomplete crosslinking, which might weaken the polymeric network and make it easier to destroy In thin adhesive films it is possible that adsorbed water on the bonding surface could interfere with the urethane curing chemistry In the few measurements made in this study, thin films of lab-prepared Halthane 73-18 did indeed exhibit larger sol fractions than did bulk samples

Mechanisms by which it might be possible for the W79 Type 6B units to have smaller sol fractions than the LLNL-built units can only be speculated One possibility is that the sol fraction initially present in the older units was been chemically incorporated back into the network, perhaps by interaction with compounds and degradation products from the LX-10 high explosive However, the most obvious reaction, oxidation by $\mathrm{NO}_{2}$ from the $\mathrm{HMX}$ in $\mathrm{LX}-10$, would seem more likely to result in chain scission rather than addition, which would increase rather than decrease the sol fraction Additional experiments would need to be conducted to determine if Halthane adhesive films are indeed altered by prolonged contact with LX-10

\section{Acknowledgments}

Thanks go to Ing Chiu for conducting the experimental work and George Dorsey at $\mathrm{Y}-12$ for providing samples of aged Halthane 73-18 


\section{Appendix A}

\section{Halthane 73-18 Information}

\section{Composition:}

- PART "A" (Halthane 73)

$\begin{array}{lll}\text { PolyMeg 1000 } & 476 w t \% & \text { Polyol } \\ \text { PolyMeg 2000 } & 74 w t \% & \text { Polyol } \\ \text { MDI } & 450 w t \% & \text { Diisocyanate }\end{array}$

- $\quad \underline{\text { ART "B" }}(\mathrm{HGH}-18)$

$\begin{array}{lrl}\text { PolyMeg } 1000 & 85 \mathrm{wt} \% & \text { Polyol } \\ \text { Butanediol } & 10 \mathrm{wt} \% & \text { Diol chain extended } \\ \text { Quadrol } & 5 \mathrm{wt} \% & \text { Tetrafunctional crosslinker }\end{array}$

\section{Preparation:}

- Add 35 parts by weight of Part "B" to 65 parts of Part " $A$ " and mix

\section{Curing:}

- Pot Life $72 \mathrm{~min}$ (100 grams)

- Handling time $16 \mathrm{hrs}$

\section{Special Notes:}

- HGH-18 crystallizes on setting Before use, crystallized material should be heated to $\sim 50^{\circ} \mathrm{C}$ to dissolve the crystals The material must be cooled back to loom temperature before use

- Cure at room temperature cure produces opaque white material

- Cure at $100^{\circ} \mathrm{C}$ produces transparent material 


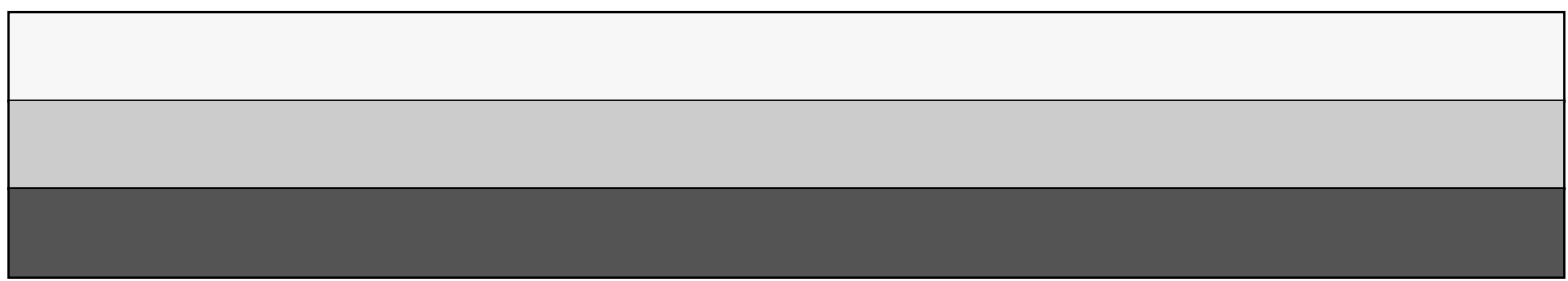

